\title{
A review on waste heat recovery from exhaust in the ceramics industry
}

\author{
Bertrand Delpech ${ }^{1, *}$, Brian Axcell ${ }^{1}$, and Hussam Jouhara ${ }^{1}$ \\ ${ }^{1}$ Institute of Energy Futures, RCUK Centre for Sustainable Energy Use in Food Chains (CSEF), Brunel \\ University London, Uxbridge, UB8 3PH, UK
}

\begin{abstract}
Following the energy crisis in 1980, many saving technologies have been investigated with attempts to implement them into various industries, one of them is the field of ceramic production. In order to comply with energy saving trends and environmental issues, the European ceramic industry sector has developed energy efficient systems which reduced significantly production time and costs and reduced total energy consumption. The last achievement is of great importance as the energy consumption of the ceramic process accounts for a significant percentage of the total production costs. More precisely, the firing stage consumes the highest amount of energy during the whole ceramic production process. The use of roller kilns, fired by natural gas, involves a loss of $50 \%$ of the input energy via the flue gas and the cooling gas exhausts. This review paper briefly describes the production process of the different ceramic products, with a focus on the ceramic sector in Europe. Due to the limited on waste heat recovery in the ceramic industry, other high temperature waste heat recovery applications are considered in the paper, such as in concrete and steel production, which could have a potential use in the ceramic industry. The state of the art technologies used in the ceramics industry are reviewed with a special interest in waste heat recovery from the ceramic process exhaust stacks and energy saving technologies.
\end{abstract}

\section{Introduction}

Ceramic components are defined as non-organic, non-metallic materials that are consolidated using heat. The solidification of the ceramic based products takes place in a high temperature kiln, usually for a prolonged duration. However, the application of high temperature heat is by definition an energy intensive process $[1,2]$. The energy consumption is reflected in the associated cost contribution, and there is a clear indication that a significant percentage of the total production costs is for energy consumption [3]. Studies on energy saving and the quality of ceramic products have highlighted that the implementation of energy saving technologies is crucial in response of the worldwide energy crisis and environmental issues but also for product quality and cost reduction [4-6].

\footnotetext{
* Corresponding autor: bertrand.delpech@,brunel.ac.uk
} 
The European ceramics sector is divided in two different sectors: "traditional ceramics" (wall and floor tiles, tableware and sanitary ware) and "advanced ceramics" (electronical ceramics, technical ceramics, and bio ceramics) [7]. The tile ceramic industry is the largest sector within the traditional ceramics. Tile manufacture represents $75 \%$ of the total energy consumption; sanitary ware $15 \%$ and the table ware $10 \%$ (Fig. 1 ).

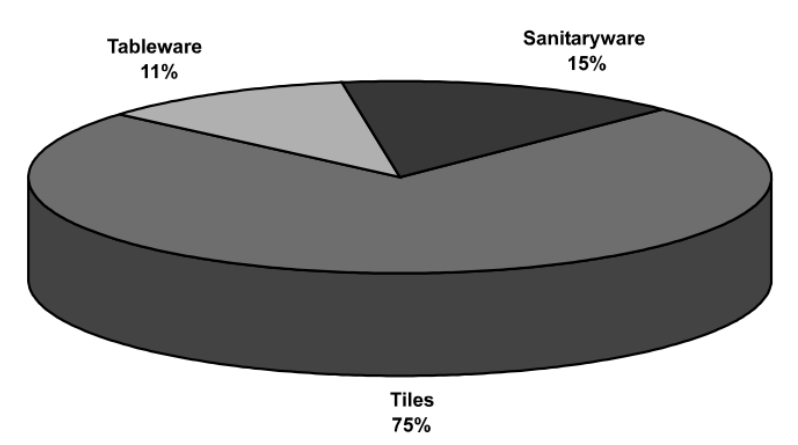

Fig. 1. European ceramics industry by energy consumption [7].

\section{The ceramic tile manufacturing process}

The mass-production manufacturing process of ceramic prismatic goods (shown in Fig. 2) is composed of four main stages: preparation of raw material, shaping, drying and firing $[8,9]$.

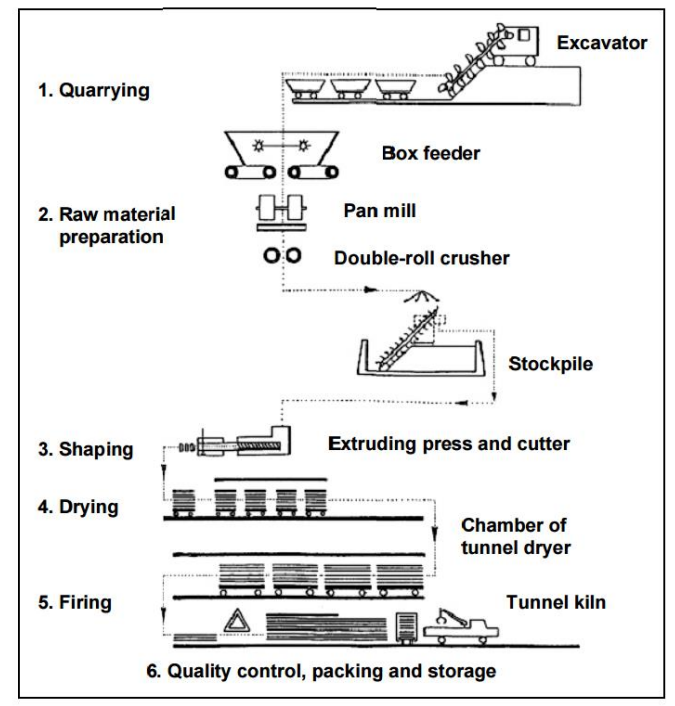

Fig. 2. Schematic view of preparation of extruded bricks in masonry brick manufacture [10].

\subsection{Preparation of raw materials and shaping/forming of ware}

A vast range of raw materials can be used by the ceramic industry to implement and expand the products range depending on the chosen product functionality. A combination of natural and synthetic materials can be used. Products manufactured for such as wall and floor tiles, household ceramics and sanitary ware products consist of aluminium silicates and clay based 
materials. The prepared raw materials are mixed in controlled proportions and homogenised to achieve chemical uniformity. Then the raw material is passed through a mechanical/hydraulic press. The shaping/forming stage is conducted when the material reaches the desired viscosity; typically, a softer (wetter) mix will require a higher heat energy during the drying stages which will eventually lead to higher drying shrinkage. The shaping process is called the soft-mud process, the machine allow the mud to flow in a pre-sanded mould to obtain the shape. An external vibration can be applied to the mould to ensure a complete fitting and to consolidate the mix. When the raw material has achieved the desired the shape of the mould, the part is send to the drying stage [10].

\subsection{Process of the drying stage}

Traditionally, clay products were dried naturally by standing in the ambient air; usually during summertime, and left until dried. The modern ceramic industry needs a drying process that is efficient in both drying speed and low wastage. Heat for the drying air is mainly supplied by a combination of gas heaters and hot air recovered from the cooling zone of the firing kiln. The heat for drying air can be supplied by cogeneration or other fuels.

The response of different materials depends on the drying process and this subsequently affects the drying times. We can identify two different drying stages during this process, the first stage is an initial warming-up period in high humidity conditions followed by the main drying stage using hotter and drier air. The most difficult drying aspect is the removal of any residual water content left within the product

The most common type of dryer is the tunnel dryer. These dryers consist of long tunnel structures with a line of carts loaded with the ceramic clay products. This continuous drying is achieved by high temperature air flowing within the tunnel. As heat is applied to the product, the humidity content within the tunnel will gradually increase. The length of the tunnel depends on the material and the moisture content in the product. Due to the high intensity heat requirements, approximatively $26 \%$ of the total $\mathrm{CO}_{2}$ emissions are produced during the drying stage [11]. This drying stage is crucial, in order to prepare the product for the firing stage [10].

\subsection{The firing stage}

The purpose of the firing stage is to increase the structural integrity of the product, for example the mechanical strength, abrasion resistance, dimensional stability, resistance to water and chemicals, and fire resistance. The product is fired at a temperature which depends on the chemical composition of the ceramic clays, the typical firing range is $750^{\circ} \mathrm{C}-1800^{\circ} \mathrm{C}$. The firing requires a significant amount of energy, and this is reflected in the contribution to emissions. Recent data suggest that the firing stage contributes $57 \%$ of the total $\mathrm{CO}_{2}$ emissions of the tiles ceramics process [11].

Tunnel kilns are commonly utilise in the ceramics industry for the firing stage [10]. As for the drying stage, the products are placed on carts. The carts are moved through the kiln at set intervals. 


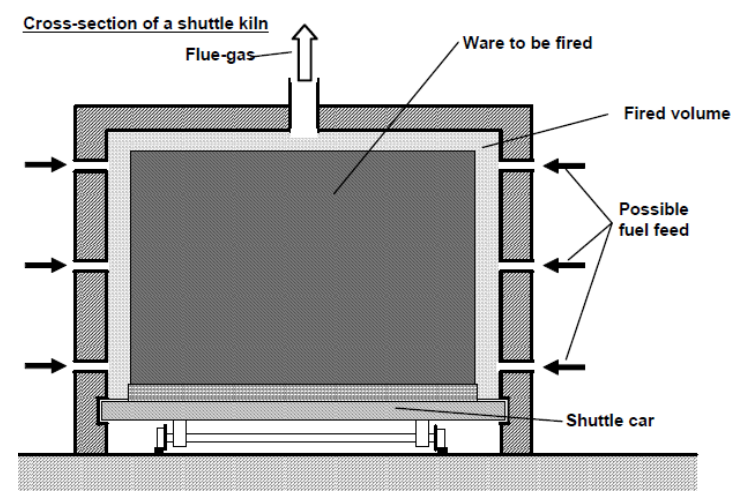

Fig. 3. Cross-section of a shuttle kiln [10].

After the firing, the products are cooled, machined and polished.

\section{Optimisation of the drying stage}

Several optimisations have been tested and applied in the drying stage such as [7]:

- Optimisation of the recirculation of drying air: using more sophisticated ventilation techniques to control fundamental parameters such as relative humidity, temperature and flow rate improved the efficiency of the hot-air dryer.

- Waste Heat recovery: Clean hot air from the cooling exhaust of the firing kilns is available and can significantly improve the efficiency of the process. Waste heat recovery can provide up to $100 \%$ of potential energy saving for the drying process.

- Pulsed hot air: A periodically interrupted flow allows the use of higher drying air temperature; this solution allows enough time for the moisture to migrate from the centroid to the surface. These higher drying air temperatures allows a reduction of 40 min when compared with the process with a classic roller dryer.

- Microwave drying: Microwave assisted drying has two obvious advantages. First of all, only the object is heated, whilst the chamber remains cool and so the energy to heat the drying chamber is saved. The microwave also heats the centre of the body and not only the surface; this promotes moisture migration to the surface. Water absorbs the microwave better than the raw materials, which considerably accelerate the drying. The use of microwave technology can significantly reduce the drying time (from 7 to 30 minutes, depending on the object/material), with a higher energy efficiency [12].

\section{Waste heat recovery}

A significant number of investigations have been conducted regarding the waste heat recovery from the kiln cooling stage. The best available technique for waste heat recovery in ceramic industry have been summarised by [10].

\subsection{Recovery of excess heat from roller kilns}

Hot air from the cooling zones of tunnel kilns is usually used in the drying stage, and added to the hot air from gas burners. This method of recovering hot air can be managed only if the 
length of the pipes (distance between the cooling and the drying zone) is limited. A significant amount of insulation is needed over the pipe section to limit thermal losses. A large amount of energy is saved using this technique of heat recovery. Some processes also use a heat exchanger to recover the heat from the cooling zone to preheat the combustion air and the air for the drying stage. The application is limited due to the production of acidic combustion gases and other implications such as foaming. Some applications use a thermal oil as a working fluid to transfer the recovered heat to the drying and firing stages $[10,13]$.

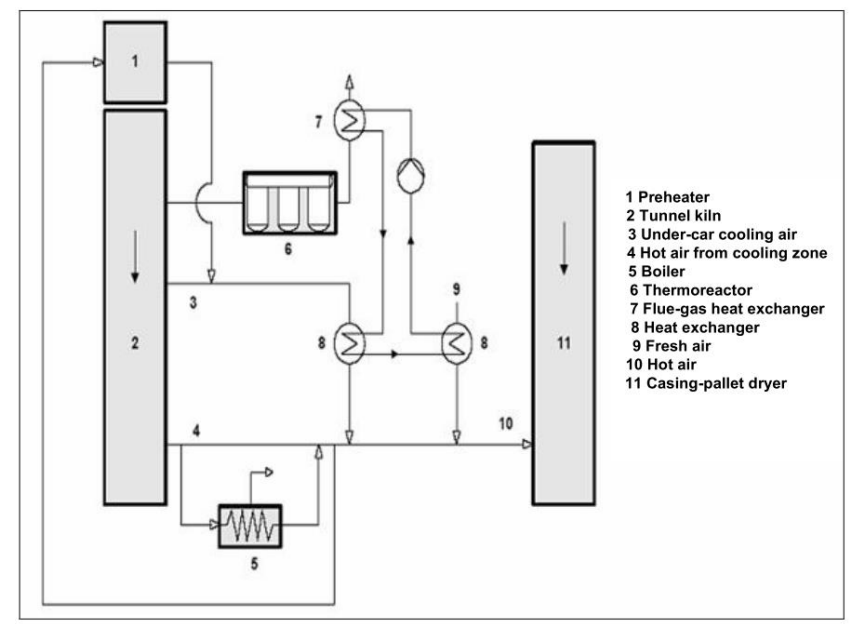

Fig. 4. Schematic view of a combined heat recycling system.

\subsection{Cogeneration/combined heat and power plant}

Cogeneration systems can be applied in the ceramic sector due to the simultaneous need of heat and electricity. The cogeneration technology has been applied in the ceramic industry to recover the waste heat from the cooling stage [10].

Figure 5 highlights the possible configuration used for a cogeneration system. The hot air from the drying stage is used in the dryer and in the cogeneration system via a heat exchanger placed in the kiln cooling zone.

Fresh air from the factory is injected into the system (high radiation from the kiln and the drying can be recovered). The fresh air is mixed with the hot air coming from the cooling stage and the hot air coming from the cogeneration system and other gas engine emissions from the factory. Then, the hot air is sent in the dryer, a gas burner maintains the desired heat in the dryer. If the hot air temperature is too high, the uncooled gases from engines are withdrawn immediately. With this process, $10 \%$ to $50 \%$ of the heat input can be saved [9, $14]$. 


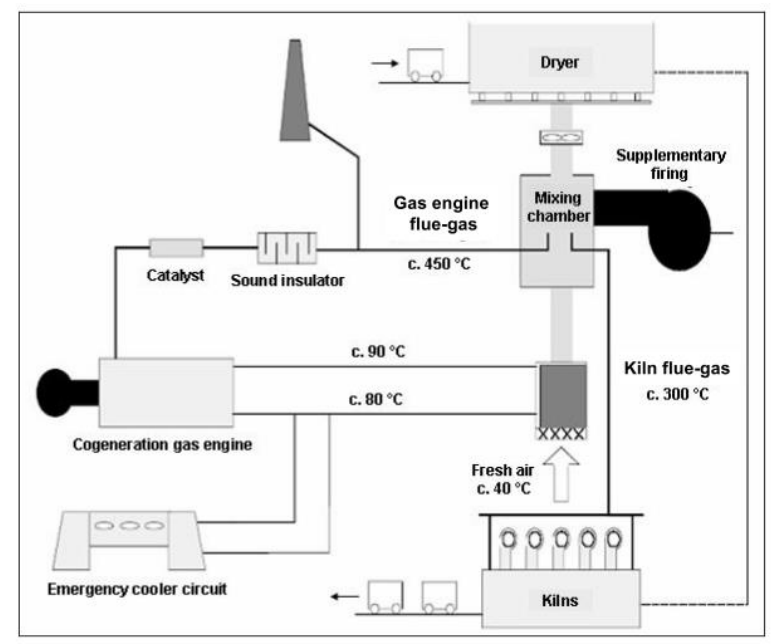

Fig. 5. Schematic view of hot air generation using a cogeneration system [9].

\subsection{Organic Rankine cycle $[15,16]$}

The application of the ORC for the ceramic industry has been investigate by B. Peris et al. [15]. The ORC has proven its efficiency for waste heat recovery from low grade heat sources. Similar to the Rankine cycle, the operative principle consist of recovering the waste thermal energy from a heat source via a working fluid to an expander in order to produce mechanical work which is subsequently converted to electricity.

The heat is taken from exhaust gases from a ceramic furnace via a collector heat exchanger to the ORC (Fig. 6).

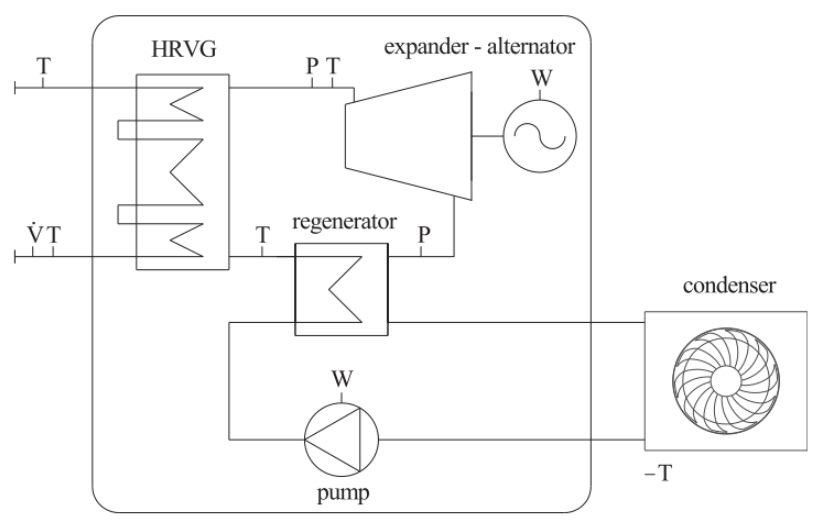

Fig. 6. Schematic of an Organic Rankine Cycle [10].

A simulation of the ORC system during a typical year of production has been conducted. The final results show an energy production for the whole year in excess of $115 \mathrm{MWh}$. This ORC could save around $237 \mathrm{MWh}$ of primary energy and avoid about 31 tonnes per year of atmospheric $\mathrm{CO}_{2}$ emissions [15]. The payback of the ORC is around 4-5 years [15]. 


\subsection{Heat pipe systems}

Waste heat recovery using heat pipe based heat exchangers has been conducted in many industrial sectors but not the ceramic tile sector. W. Srimuang and P. Amatachay have compiled a review of the applications of heat pipe heat exchangers for heat recovery in air-to-air waste heat recovery [17]. They used 3 types of heat pipe, a conventional heat pipe, two-phase thermosyphon, and oscillating heat pipes (Fig. 7). The use of heat pipe in waste heat recovery present many advantages. The design of the heat pipe ensures no cross contamination between the exhaust air and the air supply. The effectiveness of a heat pipe based heat exchanger is higher than for a conventional heat exchanger. The heat pipe system tend to be more compact, with fewer mechanical parts and minimal pressure drops. Such a system ensures a complete separation between the hot and cold flows and a high reliability, with minimal need for maintenance [18].

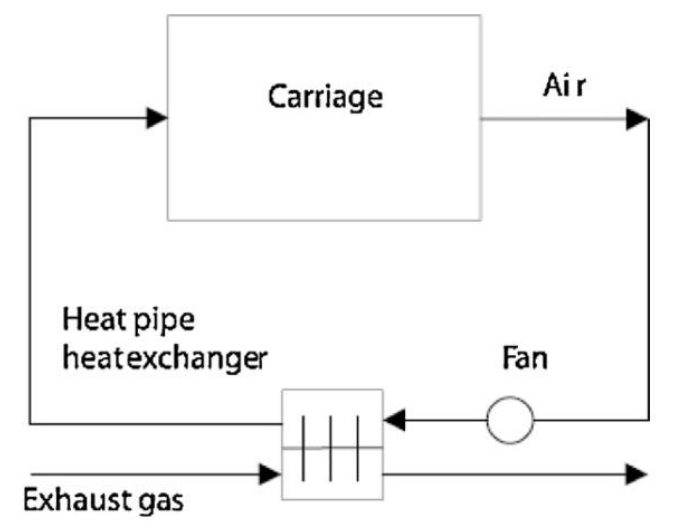

Fig. 7. Schematic of a heat pipe based waste heat recovery system [17].

\section{Conclusion}

The energy crisis of the 1980s initiated the development of many energy saving technologies. Over the last 20 years, the technologies developed and implemented allow a reduction of greenhouse gas emissions and fossil fuel consumption.

Technological innovations have been applied in large scale ceramic plants and are primarily focused on energy saving systems, for example, by control of air parameters during the drying process, pulsed air drying, and microwave drying and especially by waste heat recovery. Technologies have also been developed to improve the roller kiln technology with combined heat and power generation and again waste heat recovery. Current research in the ceramics sector is more focused on product quality, process optimisation and reducing the environmental impact of the large scale processes. Further improvements could be implemented with systems such as heat pipe heat exchangers and Organic Rankine Cycles.

\section{References}

1. E.F.S. Ciacco, J.R. Rocha, A.R. Coutinho, Appl. Therm. Eng. 113, 1283 (2017)

2. S. Kuhtz, C. Zhou, V. Albino, D.M. Yazan, Energy, 35, 364 (2010)

3. H. Reh, Tableware and Sanitaryware Plants Follow Developments in the Tile Industry (Ceram. Engng. Sci. Proc, 1995)

4. J. de Beer, E. Worrell, K. Blok, Stud. Environ. Sci. 65, 1081 (1995) 
5. E.A. Abdelaziz, R. Saidur, S. Mekhilef, Renew. Sustain. Energy Rev. 15, 150 (2011)

6. M. Croucher, Energy Policy 45, 304 (2012)

7. C. Agrafiotis, T. Tsoutsos, Appl. Therm. Eng. 21, 1231 (2001)

8. A. Mezquita, J. Boix, E. Monfort, G. Mallol, Appl. Therm. Eng. 65, 102 (2014)

9. O. Rentz, A. Schmittinger, R. Jochum, F. Schultmann, 44 (2001)

10. European Comission, 210 (2007)

11. J. Peng, Y. Zhao, L. Jiao, W. Zheng, L. Zeng, Energy Procedia 16, 467 (2012)

12. Anonymous 5, 230 (1995)

13. A. Mezquita, J. Boix, E. Monfort, G. Mallol, Appl. Therm. Eng. 65, 102 (2014)

14. J. Beltran, Cogeneration Systems in the Ceramics Tile Sector, Proceedings of the Workshop on New Technologies for the Rational Use of Energy in the Ceramics Tiles Industry, DG for Ene (EC, Castellon de La Plana, Spain, 1994)

15. B. Peris, J. Navarro-Esbrí, F. Molés, A. Mota-Babiloni, Energy 85, 534 (2015)

16. H. Tian, G.Q. Shu, in Org. Rank. Cycle Power Syst. 613-636 (2017)

17. W. Srimuang, P. Amatachaya, Renew. Sustain. Energy Rev. 16, 4303 (2012)

18. H. Jouhara, H. Merchant, Energy 39, 82 (2012) 